\title{
The demand for health: theory and applications
}

\author{
ADAM WAGSTAFF \\ From the Centre for Health Economics, University of York, Heslington, York YO1 5DD
}

SUMmaRY The concern of this paper lies with the economic theory of the "demand for health". It develops a conceptual apparatus for analysing the interaction of socioeconomic determinants of health and indicates how this can be used to shed light on a variety of topical policy issues such as socioeconomic inequalities in health and the design of prevention policies. It is written with the aim of making what has hitherto been a mathematically sophisticated literature accessible to the non-economist.

The last few years have seen a growing appreciation of the fact that health is determined by many factors among which medical care is only one. Indeed, it has become increasingly accepted that medical care is not usually the major determinant of health. Other determinants, such as food, heating, housing conditions, and work environment, play equally if not more important roles than medical care. ${ }^{1}$ There has also been a growing realisation that very little is known about the effectiveness of much of modern medicine. ${ }^{2}$ Such evidence that does exist indicates that modern sophisticated techniques are often less effective than the simpler techniques they replace. ${ }^{3}$ Some go further and argue that medical care frequently impairs health rather than improves it. ${ }^{4}$

Partly as a result of the growing realisation of the importance of non-medical influences on health, there has been a noticeable shift of emphasis in discussions concerning health policy away from strictly medical issues. One issue currently receiving a good deal of attention is that of prevention. It is often asserted that one of the most effective and, possibly, efficient ways to achieve further improvements in the quality and length of life in the developed world would be to concentrate efforts on trying to encourage a switch from health-endangering to health-enhancing consumption patterns. ${ }^{5}$ However, in order to assess the relative efficiency of alternative prevention-orientated policy measures, the costs and benefits associated with each measure must be known. In order to ascertain the benefits of a prevention strategy aimed at reducing lifestyle-related morbidity and mortality, one would need to know inter alia how the proposed measures will alter health-related behaviour.

Another issue currently of concern is that of socioeconomic inequalities in health. The recent
Black Report ${ }^{6}$ indicated that inequalities in health between social classes in Britain are in some respects as pronounced as they were 50 years ago despite the introduction in 1948 of a National Health Service aimed explicitly at eliminating inequalities in access to health care. It has been argued by the authors of the Report and others that class differences in health almost certainly stem more from class differences in lifestyles and living conditions than from differences in health care utilisation. However, to attempt to determine whether it is differences in lifestyles or differences in living conditions which are responsible for class differences in health makes little sense from an economist's perspective, since individuals' lifestyles are likely to depend in part on their resources (ie, "living conditions"), in both a narrow sense (income and financial wealth) and a broad sense (educational attainment, for example). ${ }^{7}$ Thus class differences in lifestyle almost certainly stem partially from class differences in resource availability.

Another issue currently under debate concerns the impact of unemployment on health. It has been argued that involuntary unemployment may result in serious deteriorations in the mental and physical health of those concerned. ${ }^{8}$ Such effects are thought to arise in part from the financial hardships associated with unemployment and in part from the stress that it generates (which may be due partly to the financial hardships). Seeking to assess the extent to which unemployment does carry risks to health is not an easy task, in part because those who are relatively disadvantaged in terms of unemployment histories also tend to be disadvantaged in other respects, for example, having low incomes when in work, living in poor housing conditions, and having had comparatively little education. ${ }^{9}$ Failure to take 
into account these confounding influences will result in wrongly attributing to unemployment poor health brought about by the omitted factors. ${ }^{10}$

The shift in emphasis in policy debate away from strictly medical matters towards issues such as these has resulted in a recognition of the need to bring into the debate others from outside the medical profession. None of the issues of prevention, inequalities in health, and the health consequences of unemployment can be addressed in a satisfactory manner without an understanding of health-related behaviour: the relative efficiency of alternative prevention strategies cannot be established in the absence of information on their capacity to modify health behaviour; the relative importance of inequalities in different types of resources cannot be determined unless there is an understanding of the links between resources, behaviour, and health; nor can the magnitude of any adverse health consequences on unemployment be ascertained in the absence of a behavioural model indicating the strength of the relationships between other health determinants and health. The purpose of this paper is to develop the economics approach to analysing health behaviour and to indicate the insights it affords into each of the issues discussed above. The paper is written with the non-economist in mind and requires no previous knowledge of economics. It begins by introducing the basic concepts of the approach and then indicates how these concepts can be brought together to analyse the effects of preventive policies, the causes of inequalities in health, and the impact of unemployment on health. The paper ends with a brief discussion of the usefulness of the approach.

\section{Basic concepts of the economics approach}

The economics approach emphasises the role of economic factors in shaping health-related behaviour. It is referred to as the "demand for health" approach 112 since it views the individual as "demanding" a commodity "health". It is built up around three concepts.

THE INDIFFERENCE MAP

Health (or good health) is assumed to be desirable; it is assumed not to be the only desirable thing in life, nor valued above all else. There are various reasons why good health might be thought to be desirable: for one, it is in itself pleasant (or, equivalently, ill-health may be viewed as being in itself unpleasant). Being in good health also permits one to engage in one's normal activities - social activities, work, and so on. It is clear too, however, from our behaviour both as individuals and collectively that good health is not valued above all else. Every year patients in hospitals are denied life-saving treatments because the resources society has made available to the hospital sector are insufficient to "save" every life that could from a purely technological point of view be "saved". The resources are devoted instead to other things that society values, such as good roads, sports facilities, education, and defence. At an individual level, if people valued their health above all else, they would not over-eat, smoke or drive too fast. That people do engage in such activities, and that society does spend money on sports facilities and roads when people are left to die before they need to, makes it clear that although people do value their health, they do not place an over-riding value on it.

This idea can be stated more precisely. Suppose health can be measured in terms of "units of health". For brevity, the "other things in life" from which pleasure is derived can be labelled "consumption". In what follows "consumption" means a bundle of consumption activities. Figure 1 shows units of health plotted along the horizontal axis and units of consumption plotted along the vertical axis. Any point on the graph represents a combination of health and consumption. Thus point a represents the $\frac{\rho}{\odot}$ combination 1 unit of health and 2 units of $\varrho-\overrightarrow{7}$ consumption. Above, it was assumed that people derive pleasure from being in good health and from $\delta$ undertaking consumption activities. Thus a person would experience a higher level of well-being at point $\frac{1}{6} \cdot \vec{\bullet}$ $\mathrm{b}$, for example, than at a, since at b he enjoys better health and consumes more than at point a. In general, the further the individual is away from the origin 0 , the higher will be his well-being.

The assumption above can be expressed in diagrammatic form using an "indifference curve" or

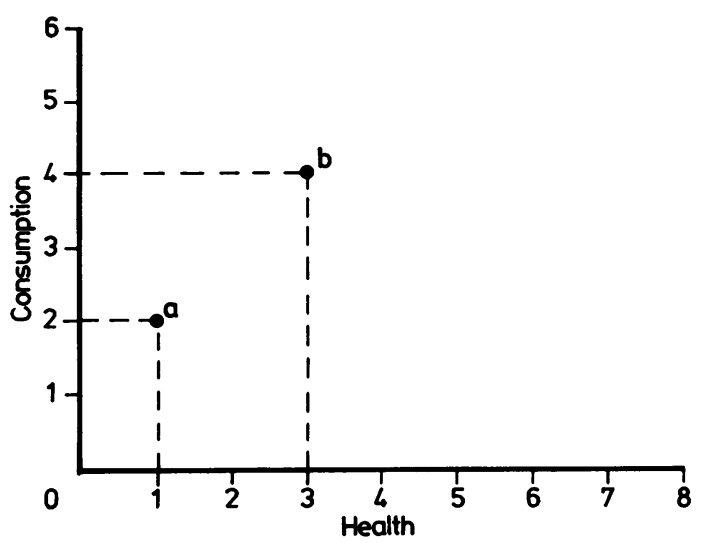

Fig 1 
"welfare contour". In the same way as a contour on a map links all places of the same height, the welfare contour in fig 2 links all points giving rise to the same level of well-being. Because all the combinations of health and consumption along the contour yield the same level of welfare, the individual is "indifferent" between them all. Hence the term "indifference curve".

The indifference curve slopes downwards because people value both health and consumption but do not view being in good health as so important that it takes priority over everything else. At point a in fig 2 the individual has 4 units of health and 1.8 units of consumption. The indifference curve indicates that if he were to move to point $b-2 \cdot 6$ units of consumption and 3 of health - he would be just as well off as he had been at a. His health would be worse, but the increase in consumption of 0.8 units would be sufficiently large to compensate for this deterioration in health. The welfare contour slopes downwards, therefore, because to compensate for a reduction in health, consumption has to increase and vice versa. The indifference curve indicates that to compensate for a reduction in health from 3 to 2 units the individual would require $1 \cdot 4(4 \cdot 0-1 \cdot 6)$ units of consumption. At $c$ the individual would be as well off as at $b$ and $a$. However, as one moves down the indifference curve it becomes increasingly difficult to induce the individual to accept further deteriorations in his health. To part voluntarily with 1 unit of health starting at point a, he has to be compensated with 0.8 units of consumption. Starting from point b, however, he has to be compensated with 1.4 units of consumption. This reflects the assumption that as successively more units of health are taken away from the individual, he will require successively more units of consumption in compensation. (Or, equivalently, as the individual is given successively more units of health, he will require successively fewer units of consumption in compensation.) It is this (not

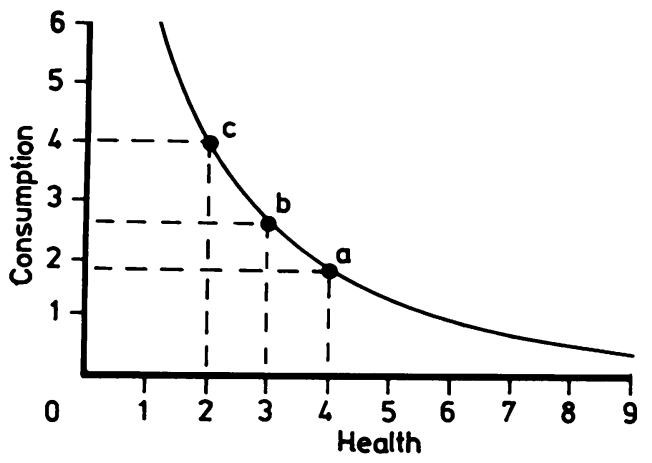

Fig 2 unreasonable) assumption that gives the indifference curve its bowed shape.

The indifference curve in fig 2 is just one possible indifference curve. Any number of these curves can be drawn, all with the same shape, some closer to the origin than that in fig 2 and some further out. While the individual is indifferent between points along a given curve, he is not indifferent between the curves themselves. He will prefer $\mathrm{IC}_{2}$ to $\mathrm{IC}_{1}$ in fig 3 , for example, since $\mathrm{IC}_{2}$ offers him more consumption for a given level of health. The individual will therefore seek to attain the highest possible indifference curve. It cannot be said yet, however, on which indifference curve he will operate. In order to determine that, the other elements of the economics approach have to be introduced.

\section{THE HEALTH PRODUCTION FUNCTION}

The second assumption on which the present approach is based may be stated as follows. Individuals exert a relatively high degree of control over their health by virtue of the fact that they can influence their health-affecting consumption patterns, their health care utilisation, and their environment. This assumption can be expressed rather more precisely using the concept of the "health production function". In economics one speaks of firms "producing" their outputs by combining "factor inputs", chiefly labour and machines. The relationship linking these inputs to the final output is known as the "production function". The "demand for health" approach utilises these ideas and conceives of the individual "producing" his health by combining "health inputs". Medical care is an example of a health input, but, as was emphasised earlier, it is only one example of a determinant of health. As was the case with consumption activities, it is useful to talk in terms of a "bundle" of health inputs comprising food, heating, health care, and other inputs. The "health production function" links

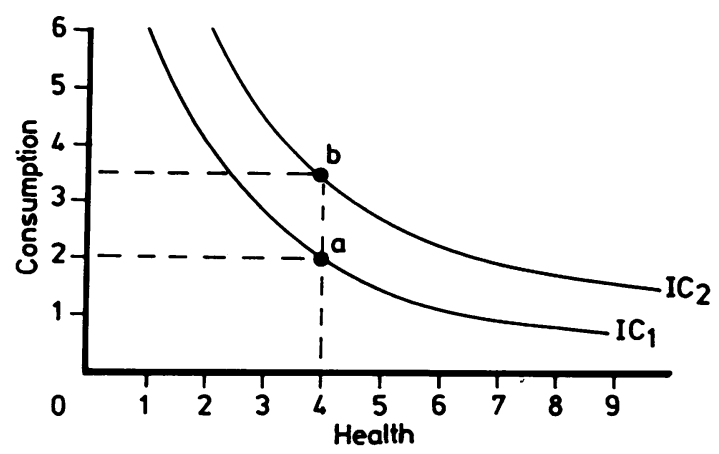

Fig 3 
these inputs to the output, health. The health production function is illustrated in figure 4 . The output-health-is measured along the vertical axis and the health inputs along the horizontal axis. Figure 4 indicates, for example, that 1 unit of health input produces 1.8 units of health. As more units of health input are used, more health is produced. Figure 4 also indicates that successive additions to the quantity of health inputs employed result in successively smaller increments in health. For example, increasing the amount of health input from 1 to 2 units results in an increase in health of 1.5 units. Increasing the amount of health input from 5 to 6 units, however, results in an increase in health of only 0.5 units. This phenomenon is termed the "law of diminishing marginal product", the term "marginal product" referring to the extra number of units of output resulting from the use of one extra unit of input. (The marginal product of health inputs in the range 1 to 2 along the horizontal axis, for example, is equal to $1 \cdot 5$.) That this principle applies in the production of health is clear from, for example, the differing experiences of developing and developed countries. At the low levels of health and health input currently prevailing in the Third World, even quite modest increases in the quantities of health input employed (food, sanitation, etc) have relatively large impacts on life expectancy. At higher levels of health and health input, such as those enjoyed by citizens of developed countries, even quite large increases in the resources devoted to the promotion of health appear to have relatively small impacts on the quantity and quality of life.

The health production function shows how much health can be obtained from a given quantity of health input for a given state of technical knowledge.
Technical knowledge is not, however, constant over time; it changes in response to breakthroughs in medical science. As medical science progresses, our understanding of the health production process increases. One would expect that, as a result of this enhanced understanding, it should be possible to produce health more efficiently, that is, more health ought to be produced per unit of health input than formerly. (A good example here is the increased understanding of the role of environmental factors in the role of infectious diseases.) When the state of technical knowledge changes, the position of the health production function changes. As knowledge increases, so the production function shifts upwards. This is illustrated in figure 5. With the old-lower-health production function, 4 units of health input yielded 4.4 units of health. On the new production function, however, 4 units of health input produce 5.4 units of health.

As well as considering the effects of knowledge increasing over time, one can consider the implications of some individuals being more knowledgeable about the technology of health production than others. One might reasonably suppose that the better educated are in a better $\overparen{D}$ position to assimilate information about health $\frac{0}{\sigma} \vec{z}$ matters from the mass-media and their physician than the poorly educated, thereby being betterô $\frac{\hat{\rho}}{\mathrm{J}}$ equipped to produce a healthy diet from a given $\overrightarrow{0}$ outlay on food, to acquaint themselves with the mosto. efficient ways to heat their homes, and to digest? information about possible health hazards in their workplace. One may presume therefore that the position of an individual's health production function will depend on his education.

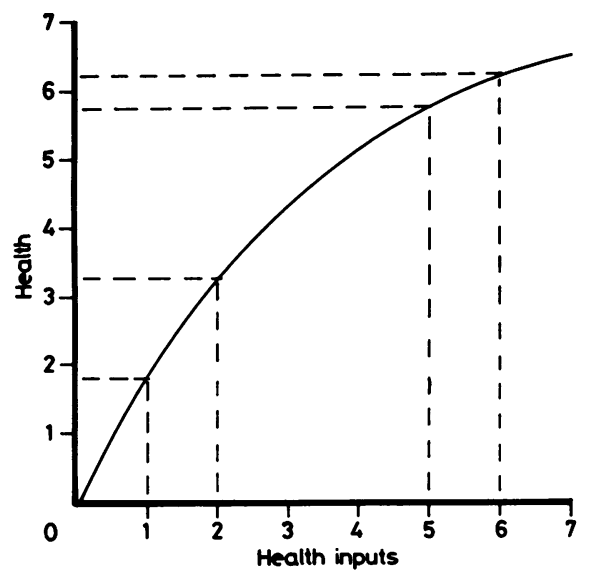

Fig 4

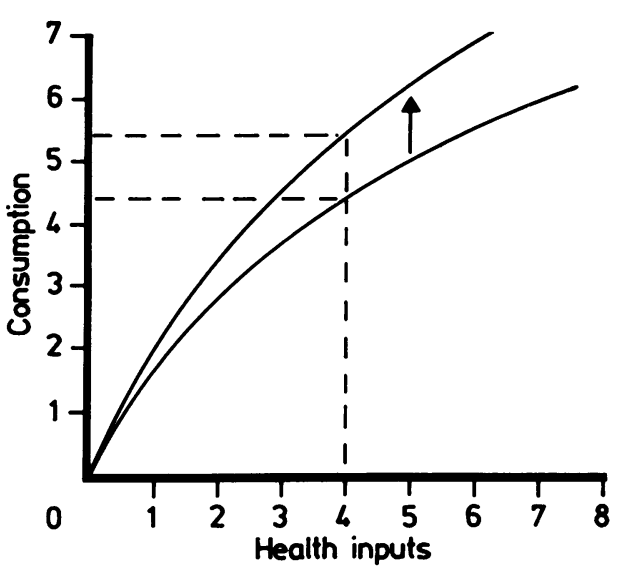

Fig 5 


\section{THE BUDGET CONSTRAINT}

We come now to the third and fourth assumptions on which the economic approach is based. The third is this: neither health inputs nor consumption activities are costless. Heating, food, housing, and health care all cost money, although the price an individual pays for each obviously varies. The significance of this third assumption becomes apparent when the final assumption is introduced: individuals have only limited resources at their disposal. The simplest version of this assumption is that individuals have a given income with which to finance their health production and consumption activities.

Suppose, for example, that the individual has an income of $£ 40.00$, that the price of a unit of consumption is $£ 10.00$ and that the price of a unit of health input is $£ 5 \cdot 00$. If he wanted, the individual could spend all his $£ 40.00$ income on improving his health. This would give him 8 units of health input. Alternatively, he could spend all his income on consumption activities. Doing so would give him 4 units of consumption. Clearly, though, he could spend part of the $£ 40.00$ on consumption and part on health inputs. He could, for example, purchase 2 units of health input and 3 units of consumption.

The various possibilities open to the individual can be illustrated by means of the "budget constraint", which indicates all combinations of health inputs and consumption which exactly exhaust the individual's income. The budget constraint is illustrated in figure 6. The diagram indicates, for example, that if all $\mathfrak{\$ 0 . 0 0}$ were spent on health inputs, the individual could purchase 8 units. He could, however, operate at point a. Here he purchases 3 units of consumption and 2 of health input. Or he could operate at point $b$, where he purchases 2.5 units of consumption (costing $£ 25 \cdot 00$ ) and 3 units of health input (costing $£ 15 \cdot 00$ ).

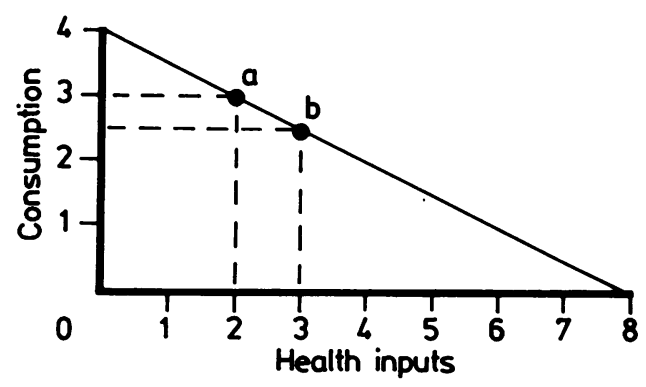

Fig 6

The slope of the budget constraint has a simple interpretation: it indicates the number of units of consumption which must be given up to obtain one more unit of health input. Starting from point a, for example, the individual has to give up 0.5 unit of consumption to obtain one extra unit of health input. This is in fact the slope of the budget line: the slope of a downward sloping line is the amount by which one descends the vertical axis to move one unit along the horizontal axis. The slope is therefore $(-) 0 \cdot 5$. This is in fact the ratio of the price of a unit of health input to the price of a unit of consumption, ie, $5 / 10=0.5$.

Suppose the prices of consumption and health inputs both double to $£ 20.00$ and $£ 10.00$ respectively. If all $£ 40 \cdot 00$ were spent on health inputs at the new prices, the individual would obtain only 4 units of health input (compared to 8 previously). If he spent all his income on consumption, he would obtain only 2 units of consumption (compared to 4 previously). The effect of a doubling of both consumption and health input prices is therefore to induce a parallel inwards shift in the budget constraint, as illustrated in figure 7 . It should be noted that the slope of the budget line is unchanged, ie, $10 / 20=0 \cdot 5$.

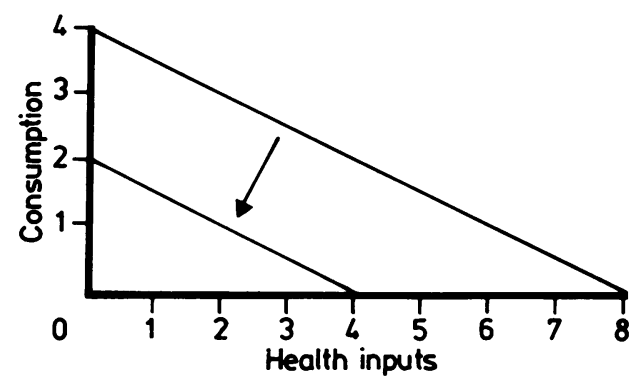

Fig 7

Suppose now that only one price changes. Suppose, for example, that health inputs become more expensive, but that the price of consumption remains the same. Let the new price of health inputs be $£ 10.00$, and the price of consumption $£ 10.00$ per unit as before. If the individual spends all his $£ 40 \cdot 00$ on consumption he still obtains 4 units. Hence the intercept of the budget line on the vertical axis remains unchanged at 4 units. Spending all $£ 40.00$ on health inputs now gives only 4 units, however, compared to the 8 units attainable previously. The budget line thus swivels about its intercept on the vertical axis, as indicated in figure 8 .

Consider next the effect of a change in the individual's income. Such a change might come about through, for example, unemployment, retirement, change of job, and so on. Suppose the individual's income increases from $£ 40 \cdot 00$ to $£ 50 \cdot 00$. Spending all $£ 50.00$ on health inputs at the old price of $£ 5.00$ per unit would give 10 units of health input, 


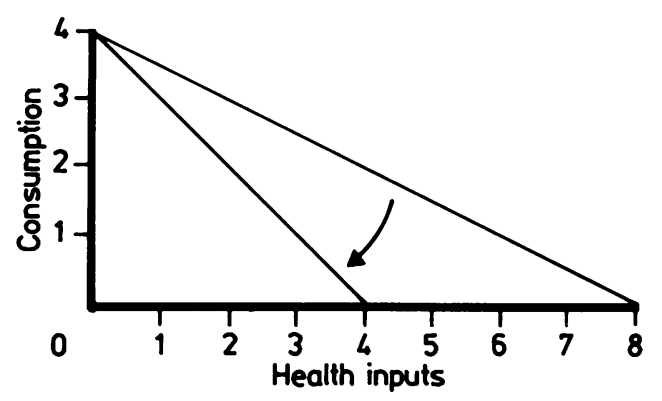

Fig 8

compared to 8 previously. Spending all $£ 50.00$ on consumption at $£ 10.00$ per unit would give 5 units of consumption, compared to 4 previously. The effect on the budget constraint is to shift it outwards, as indicated in figure 9. Note that the slope is unchanged, since the (relative) prices of consumption and health inputs are unchanged.

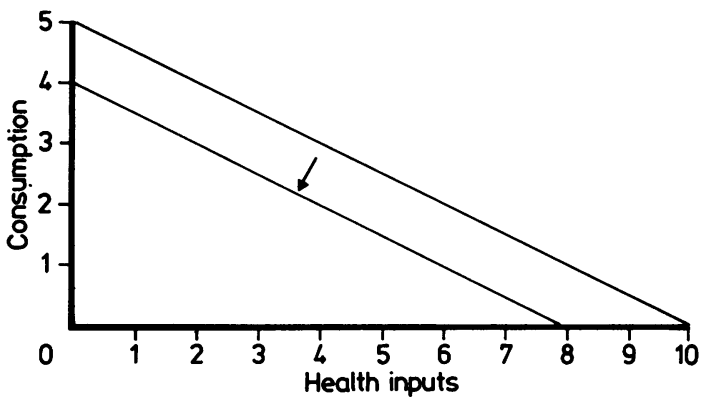

Fig 9

\section{USING THE ECONOMICS APPROACH}

To summarise briefly, the demand for health approach is built up around three basic concepts-the indifference map, the health production function, and the budget constraint. The indifference map is a means of representing diagrammatically the assumption that people value both health and other things in life but do not place an overriding value on their health. The health production function expresses the idea that people "produce" their health by utilising "health inputs", such as nutritious foods, health care, exercise, etc. Utilising more health inputs results in improved health, but successive additions to the quantity of health inputs employed result in successively smaller improvements in health. The budget constraint indicates that individuals have only limited incomes with which to finance their health production and other activities, and that neither their health production nor their other activities are costless.
Using these concepts, one can see how the individual will behave. How much health and how much consumption will he "demand"? Of more interest is to examine how he behaves in response to changes in the factors affecting his behaviour. What would happen, for example, if a policy supplementing the incomes of low-income families were introduced? Would this help to reduce socioeconomic inequalities in health? Even if it would, might there not be other more effective ways? For example, might not subsidising the prices of health inputs, such as heating, milk, etc, be a more efficient way to combat inequality? How should one go about designing a prevention-orientated health policy? Should any resources released from the hospital sector be used to finance price subsidies, or should they be used to finance health education programmes?

\section{CONSUMER EQUILIBRIUM}

Firstly, it is necessary to establish how the individual will behave. In particular, how much health will he "demand" and how much "health input" will he utilise? It can reasonably be assumed that he will tryo to do the best he can for himself, in the sense that hed will organise his expenditures on health inputs and consumption so as to give himself the highest possible level of well-being. In terms of the diagrams of the previous section, this means that he will seek to attaino the highest indifference curve available to him. In doing this he will be constrained by his limitedo income, the prices he has to pay for health inputs and consumption activities, and the opportunities open to him for transforming health inputs into health. In terms of the diagrams introduced earlier, the budget constraint and the production function act as constraints on his behaviour. The former summarises the financial constraints the individual faces and the latter the technological constraints facing him. In sum, then, the individual's objective will be to attain the highest possible welfare contour, subject to the constraint that he operates on both his budget constraint and his health production function.

To examine the individual's behaviour therefore one requires a diagram which brings together figures 3,4 , and 6 . This is done in figure 10. Each of the four quadrants are considered in turn, starting with quadrant II. Quadrant II reproduces the health production function of figure 4 . Health is still measured south to north, but health inputs are measured east to west. Quadrant III shows the budget constraint of figure 6 . Health inputs are measured from east to west and consumption from north to south. In this example, the individual has an income of $£ 40.00$, the price of consumption is $£ 10.00$, and the price of a unit of health input is equal to $£ 8 \cdot 00$. (He could spend all his income on health 


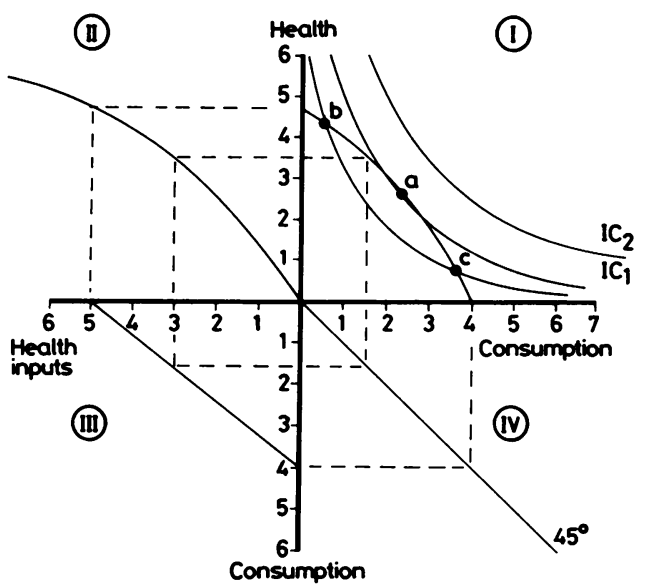

Fig 10

inputs, thereby obtaining 5 units of health input, or all on consumption, thereby obtaining 4 units of consumption. Alternatively, he could buy 3 , for example, units of health input and 1.6 units of consumption.)

By including the budget constraint and health production function in the same diagram one can see, for each amount of health input, (i) how much health can be produced and (ii) how many units of consumption could be purchased with the income left over. Employing 3 units of health input, for example, would produce 3.5 units of health and would leave enough income over to purchase 1.6 units of consumption. To see which combination of health and consumption the individual will actually choose, one needs a quadrant of the diagram showing what combinations of health and consumption are available to him, given his financial and health technology constraints, and which combinations he prefers. This is done in quadrant $I$, where health is measured from south to north and consumption from west to east.

Before discussing quadrant $\mathrm{I}$ in detail it is useful to explain quadrant IV. Here consumption is measured on both axes. The straight line going through the origin is a "45-degree" line, a device for enabling one to read units of consumption off the vertical axis in quadrant III onto the horizontal axis of quadrant I. (For example, taking 4 units of consumption on the vertical axis in quadrant III and following it anticlockwise through quadrant IV, one arrives at 4 units of consumption on the horizontal axis of quadrant $I$. This merely indicates that 4 units of consumption in quadrant III are the same as 4 units of consumption in quadrant $\mathrm{I}$.)
The curves $\mathrm{IC}_{1}$ and $\mathrm{IC}_{2}$ in quadrant $\mathrm{I}$ are the indifference curves of figure 3 . The bowed-out shaped curve in quadrant $I$ is the individual's "welfare possibility frontier" (WPF). It indicates all combinations of health and consumption which satisfy both the budget constraint and the health production function and is derived from the budget constraint and the health production function. This can be seen by following the dotted lines in figure 10 . Suppose, for example, all the individual's income was spent on health inputs. From quadrant III one can see that he would obtain 5 units of health input. Following the dotted line up into quadrant II and then rightwards across to the vertical axis, one sees that the 5 units of health input would produce 4.7 units of health. This, then, is one of the end-points of the WPF. The other is obtained by considering the situation where all the individual's income is spent on consumption. From quadrant III one can see that spending all his income on consumption would give him 4 units of consumption. Tracing the dotted line around through quadrant IV brings us, as we would expect, to 4 units of consumption on the horizontal axis in quadrant $I$. This is the other end-point of the WPF. Suppose now some intermediate point on the budget constraint is taken, for example, 3 units of health input. Reading off on the health production function, it is seen that 3 units of health input produce 3.5 units of health. From the budget constraint it is seen, too, that purchasing 3 units of health input would leave the individual with sufficient income to purchase 1.6 units of consumption. This gives, therefore, another feasible combination for the WPF-3.5 units of health and 1.6 units of consumption. If this process were to be continued for all combinations of health input and consumption satisfying the budget constraint, one would end up with the WPF indicated in figure 10 .

It is known now which combinations of health and consumption are available to the individual, namely, those on (or within) the WPF. Which of them, however, will he choose? Above it was argued that the individual would be expected to seek to attain the highest indifference curve he can, for this will give him his highest level of welfare. He will therefore operate at point a in fig 10 on the indifference curve IC $_{1}$. At this point indifference curve IC $_{1}$ is tangential to the WPF. This indifference curve is the highest he can attain while still remaining on the WPF. If he chose to operate on indifference curve $\mathrm{IC}_{0}$, for example, he could still operate on the WPF-either at b or at c-but his well-being would be lower than that expected at point a. Indifference curve $\mathrm{IC}_{2}$ is clearly not attainable, since operating on it would involve the individual operating outside his WPF. In other words, given the technology of health production, his 
income, and the prices he faces, he would be spending more on health inputs and consumption than he could afford.

EFFECTS OF CHANGES IN INCOME

In the previous section it was seen how the interaction of prices, income, and health production opportunities gives rise to an "optimal" combination of health and consumption. This section considers how this optimal combination changes when factors affecting behaviour change. This involves examining the effects of a change in one variable at a time, holding all other factors constant; for example, the effects of changing the individual's income, holding prices and health production opportunities constant.

Consider first the effects of changing the individual's income. Suppose, for example, that the individual's income falls from $£ 40 \cdot 00$ to $£ 32 \cdot 00$. This results in the parallel inwards shift of the budget constraint illustrated in figure 11 . Because the budget line has changed its position, the WPF changes its position and shape. Tracing round all the possible points on the new budget line gives a new WPF indicated by the dashed bowed-out curve in quadrant I. Not surprisingly, a lower income means that the number of feasible combinations of health and consumption open to the individual is reduced. The old optimal combination-point a-is now no longer available. The best the individual can do for himself with his new income is to operate at point $b$. Here he has a lower level of health (2.4 units compared to 2.65 previously) and consumes less. His health is lower because he has less to spend on health inputs and on consumption. Tracing the dotted line from $b$

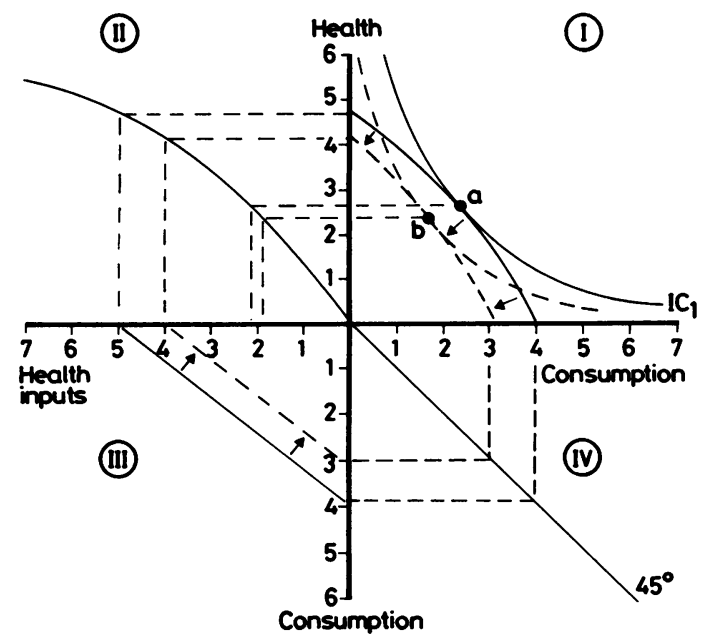

Fig 11 westwards into quadrant II one sees that he now employs only 2.9 units of health compared to the $3 \cdot 1$ he employed previously. Thus a fall in income is predicted to result in a reduction in the quantity of health inputs employed and a deterioration in the individual's health status.

These predictions are of interest from a policy stand-point. From the point of view of preventive measures, they suggest that one possible strategy for a prevention-orientated health policy would involve supplementing the incomes of those on low incomes. If low incomes are a causal factor in poor health, as the analysis above suggests may be the case, improving the health of those in poor health could be achieved by supplementing their incomes. From the inequality perspective, the predictions above suggest that socioeconomic inequalities in health stem, at least in part, from inequalities in income. One would expect, therefore, that changes in socioeconomic inequalities in health over time will reflect changes in the distribution of income between socioeconomic groups. In Britain, the distribution of income has remained relatively stable over the course of the last 15 years. In the light of the prediction derived above, it should come as little surprise, therefore, that $\bigcirc$ inequalities in health have shown so little tendency to $\stackrel{\mathbb{Q}}{2}-$ diminish. Finally, from the point of view of the unemployment health debate, the analysis above 8 leads us to expect that, to the extent that unemployment is associated with a fall in income, it is likely to lead to some deterioration in the health of the individual concerned, regardless of whether any stress effects are operating.

Suppose the individual's income falls yet further, say, to $£ 24.00$. The effect of a drop in income from $£ 40.00$ to $£ 24.00$ is illustrated in fig 12 , which

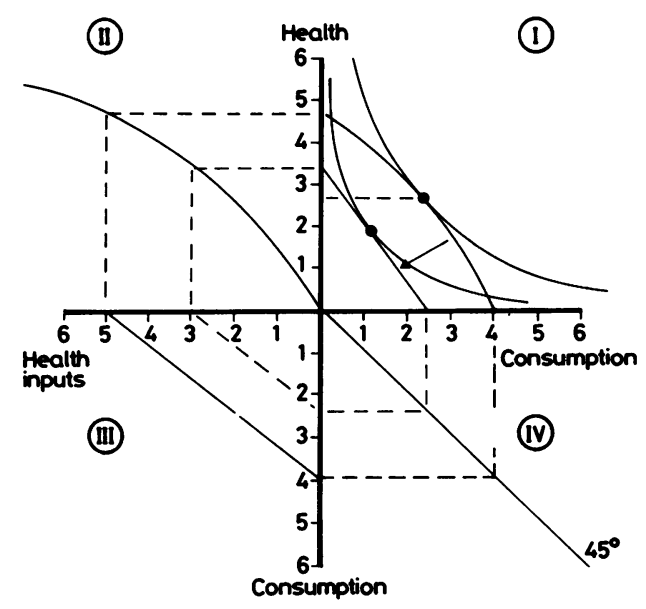

Fig 12 
indicates that at an income of $£ 24.00$ the individual demands 3 units of health. Thus reducing the individual's income from $£ 40.00$ to $£ 24.00$ results in a larger deterioration in health than reducing his income from $£ 40.00$ to $£ 32.00$. Thus the larger the drop in income, the larger will be the reduction in utilisation of health inputs and the greater will be the deterioration in the individual's health status. This prediction is also of some interest from a policy perspective. It suggests, for example, that the impact of unemployment on health will depend on the generosity of the unemployment benefit system operating in the individual's country.

If the process of taking income away from the individual is continued, one can see how much health he demands for different amounts of income. Figure 13 plots the resultant relationship between health and income. It indicates that the higher the individual's income, the greater will be his demand for health. It indicates too, however, that the relationship between health and income is not a simple linear one. If $£ 10.00$ are taken from an individual with an income of $£ 40 \cdot 00$, for example, his demand for health is reduced by 0.35 units $(2 \cdot 65-2 \cdot 30)$. If, however, $£ 10 \cdot 00$ are taken from a person with $£ 30.00$ income, his demand for health falls by 0.55 units $(2 \cdot 30-1 \cdot 75)$. This result derives from the assumption of diminishing marginal product of health inputs. At low levels of income people can afford only relatively few units of health input; the contribution of the "marginal" unit of health input is, however, quite large. Taking a given number of pounds' income away in these circumstances therefore has a more dramatic effect than taking a given number of pounds away from a high-income family. Thus a given reduction in an individual's income will result in a larger deterioration in health, the lower the individual's income. This prediction is

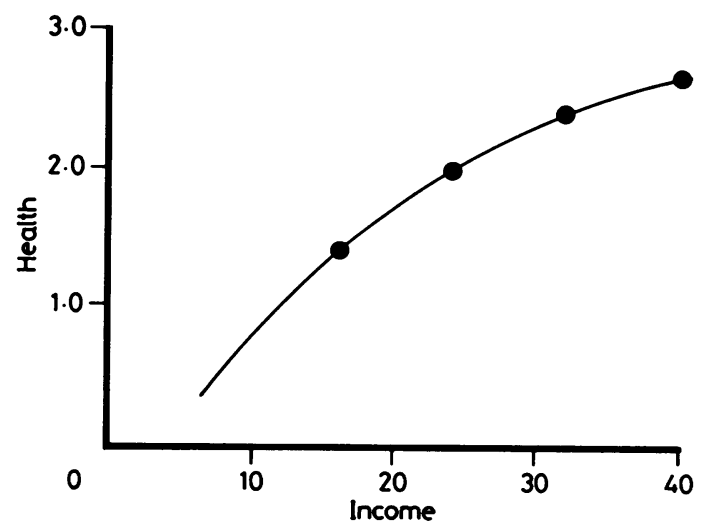

Fig 13 also of interest from the policy perspective. It suggests that income-supplements will be especially effective as a preventive measure among low-income groups. It is of interest, too, from the inequalities standpoint, suggesting that redistributing income from high-income groups to low-income groups will result in relatively small deteriorations in the health of those in the high-income groups but relatively large improvements in the health of those in the low-income groups, and that inequalities in health will be more pronounced in countries with low per capita incomes than in those with high per capita incomes. Finally, from the unemployment health perspective, the analysis above suggests that unemployment will lead to smaller impairments to health in richer countries than in poorer countries, even if the unemployment benefit systems are no more generous in the richer countries than in the poorer countries.

\section{EFFECTS OF CHANGES IN PRICES}

Also of interest are the effects of a change in the price of health inputs. Figure 14 illustrates the effects of a fall in the price of a unit of health input from $£ 8.00$ to $£ 5.90$. The effect on the budget line is to make it swivel outwards about the intercept on the consumption axis. This results in an outwards swivel of the WPF in quadrant. The end-point on the consumption axis remains unchanged. (If all income were devoted to consumption, the number of units of consumption attainable are the same before and after the health input price change.) The new optimal combination of health and consumption is indicated by point $b$ in quadrant $I$. Here the individual is in better health and, to achieve this, employs more

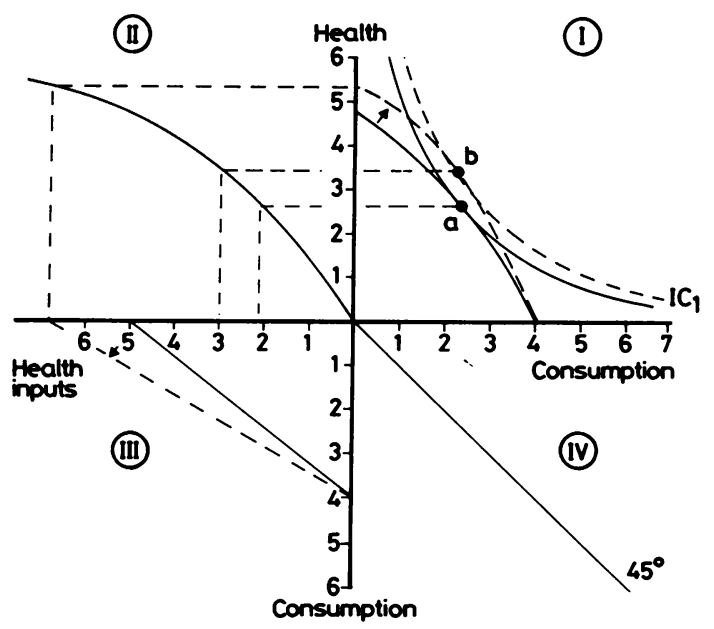

Fig 14 
health inputs. Thus, a reduction in the price of a unit of health input results in an increased utilisation of health inputs and, as a consequence, an improvement in the individual's health status. This prediction suggests that subsidising the prices of health inputs such as milk, heating, housing costs, etc, is likely to result in an improvement in the health of individuals receiving such subsidies and may therefore be an effective, although not necessarily efficient, promotion strategy.

CHANGES IN THE STATE OF TECHNICAL KNOWLEDGE

It was indicated earlier that advances in the medical sciences ought to result in the efficiency of health production. It was suggested, too, that differences between individuals in their levels of education may be associated with differences in the efficiency with which health inputs can be transformed into health. Figure 15 illustrates the effect of an upwards shift in the health production function. The upwards shift in the health production function in quadrant II results in a change in the shape of the WPF, as indicated in quadrant I. At the new position, b, the individual is in better health. His utilisation of health inputs is reduced, however, since he obtains more health per unit of health input than was the case previously. Thus an increase in the state of technical knowledge results in a reduction in the utilisation of health inputs but an increase in the demand for health.

These predictions are of interest from the policy perspective. They suggest that education and/or health-education programmes might be used in preventive health policies to secure health improvements. It is worth noting that the prediction that utilisation of health inputs is likely to decrease

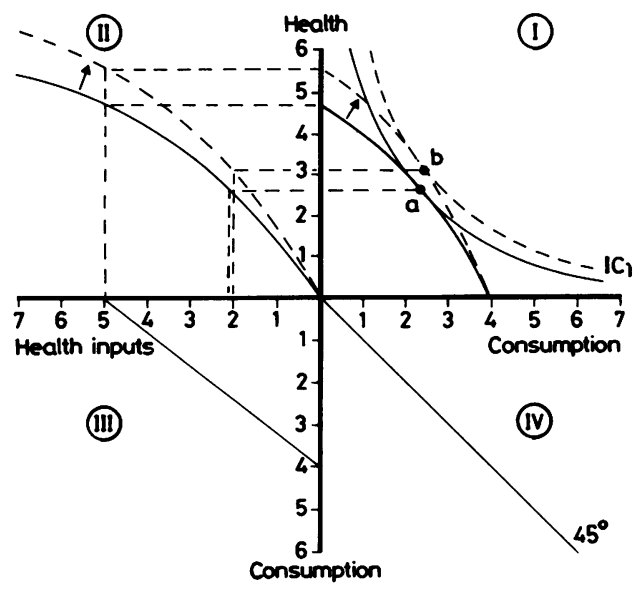

Fig 15 following an improvement in the state of knowledge, contrasts with the prediction for an increase in income. There, both health and health input utilisation were predicted to increase. This suggests that using general and/or health-education programmes as a health policy tool ought to improve an individual's health but reduce his demand on health services and other health inputs (at least at that stage in his life). The prediction suggests, too, that inequalities in education are indeed likely to be a causal factor in generating inequalities in health. This is especially true when one bears in mind the impact of education on income. Above, it was seen that, to the extent that the better educated are more efficient producers of health, they will demand more health than the poorly educated. In deriving this prediction it was assumed that the better educated and the poorly educated had the same incomes. In reality this is most unlikely to be the case: they are also likely to receive higher incomes than the poorly educated.

\section{Discussion}

The purpose of this paper has been to provide a introduction to the economic theory of the demani for health and to indicate some of its possible applications. The demand for health approach has been seen to yield a whole range of testable $\frac{9}{5}$ predictions which shed light on a variety of. $\overrightarrow{0}$ health-related issues. Some of the predictions derived may seem somewhat self-evident. The prediction that an increase in the price of health inputs should lead to a deterioration in health status is perhaps an example. Other predictions, however, are less self-evident. The predictions that a reduction in income of $£ 10.00$ will cause larger deteriorations in health at lower levels of income than at higher income levels and that the better educated should utilise fewer health inputs and yet be in better health than the poorly educated are examples. A strength of the demand for health approach to health-related behaviour, then, is its ability to yield a variety of testable predictions from relatively simple and not unreasonable assumptions. Because of this, it would seem to provide a useful conceptual apparatus with which to investigate health policy issues of the type discussed in the paper.

It should be emphasised, however, that generating predictions is only part of the exercise. The next stage involves testing the predictions against the data to examine the extent to which they are consistent with the evidence. In fact empirical work on the demand for health is only in its infancy, and it is too early yet to pronounce a final verdict. Confronting the predictions with the evidence serves also to provide estimates of the likely effect of various policy 
measures. It was seen, for example, that income-supplements and price-subsidies are both likely to result in health improvements. The theory cannot predict, however, which would be the more effective measure. It merely indicates the direction of changes, not their magnitudes.

It should be emphasised, too, that the demand for health approach provides only part of the information required by policy-makers. Theoretical and empirical analyses of the demand for health can indicate which policy measures are likely to be the most effective in tackling particular problems, but they cannot indicate by themselves which measures are likely to be most cost-effective. The demand for health framework provides information on only the benefits of particular policy measures. It therefore needs to be used in conjunction with other tools, such as cost-benefit analysis and cost-effectiveness analysis.

I wish to thank Dick Brooks, Peter Hertzman, Gavin Mooney, and Alan Williams for helpful comments on earlier drafts of this paper written while I was working at the Swedish Institute of Health
Economics and the Health Economics Research Unit, Aberdeen. The usual disclaimer applies.

\section{References}

${ }^{1}$ McKeown T. The role of medicine: dream, mirage or nemesis? Oxford: Basil Blackwell, 1976.

${ }^{2}$ Cochrane AL. Effectiveness and efficiency: random reflections on health services. London: Nuffield Provincial Hospitals Trust, 1972.

${ }^{3}$ Bunker JP, Barnes BA, Mosteller F. Costs, risks, and benefits of surgery. New York: Oxford University Press, 1977.

${ }^{4}$ Illich I. Limits to medicine: medical nemesis-the expropriation of health. Harmondsworth: Penguin, 1977.

${ }^{5}$ Department of Health and Social Security. Prevention and health everybody's business. London: HMSO, 1976.

${ }^{6}$ Townsend P, Davidson N. Inequalities in health: The Black Report. London: Penguin, 1982.

${ }^{7}$ LeGrand J. Inequalities in health and health care. London: Nuffield/York Portfolio 5, 1984.

${ }^{8}$ Moser KA, Fox AJ, Jones DR. Unemployment and mortality in the OPC Longitudinal Study. Lancet 1984: ii: 1324-9.

${ }^{9}$ Nickell S. A picture of male unemployment in Britain. Econ J 1980; 90: 776-94.

${ }^{10}$ Stern J. The relationship between unemployment, morbidity, and mortality in Britain. Pop Stud 1983; 37: 61-74.

${ }^{11}$ Grossman M. The demand for health: a theoretical and empirical investigation. New York: NBER, 1972.

${ }^{12}$ Grossman M. On the concept of health capital and the demand for health. $J$ Polit Econ 1972; 80: 223-55. 